\title{
MANAJEMEN MUTU TERPADU
}

\author{
Teguh Sriwidadi $^{1}$
}

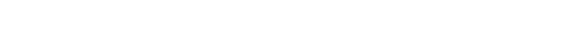
ABSTRACT

Total Quality Management (TQM) is the effort to meet or exceed the customer needs with the lowest cost. The business will successful if it can produce an output (product and service) fit according to the customer needs. They will raise the profit if only they can operate efficiently (effective cost, avoid waste, and rework ), and to ensure that all the activity directed to the effort to satisfy the customer needs.
\end{abstract}

Keywords: Total Quality Management (TQM)

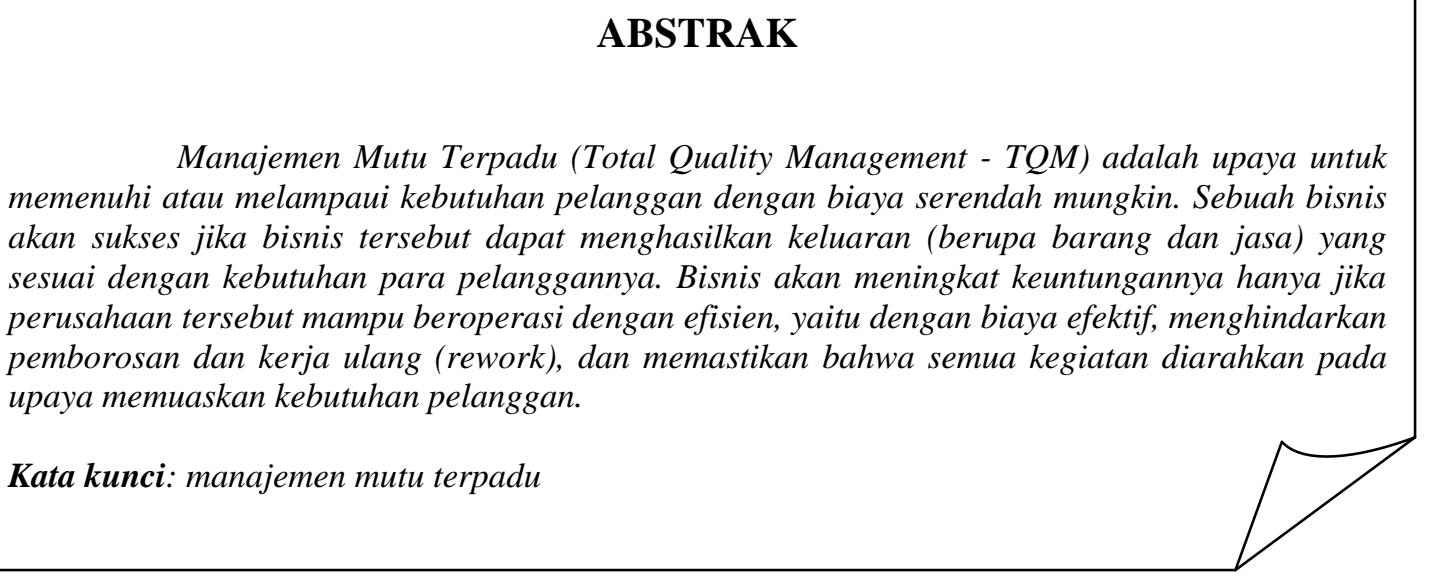

\footnotetext{
${ }^{1}$ Staf Pengajar, Fakultas Ekonomi, UBiNus, Jakarta
} 


\section{PENDAHULUAN}

\section{Memenuhi Kebutuhan Pelanggan}

Mutu secara umum didefinisikan sebagai memenuhi atau melampaui persyaratan pelanggan. Hal itu berarti produk atau jasa tepat bagi penggunaan oleh pelanggan. Ketepatan untuk penggunaan berhubungan dengan nilai yang diterima pelanggan dan kepuasan pelanggan. Hanya pelanggan - bukan produsen - yang dapat menentukannya.

Kepuasan pelanggan merupakan konsep yang relatif berbeda antara pelanggan yang satu dengan yang lain. Sebagai contoh, beberapa orang mengatakan bahwa mobil Ford sangat memuaskan sedang yang lain mengatakan tidak. Setiap orang mendefinisikan mutu sesuai dengan kebutuhan masing-masing. Dari sudut pandang produsen, variasi dalam mutu tidak dapat ditolerir. Produsen harus menentukan spesifikasi tersebut sambil terus menerus mengembangkan produknya. Apakah hasilnya memenuhi persyaratan pelanggan atau tidak, pelangganlah yang menentukannya.

Mutu dari kesesuaian berarti memproduksi suatu produk untuk memenuhi spesifikasi. Jika produk sesuai dengan spesifikasi, hal itu dianggap oleh operasi sebagai produk bermutu meskipun mutu desainnya rendah. Sebagai contoh, sepasang sepatu yang tidak mahal dapat mempunyai mutu yang tinggi jika dibuat sesuai dengan spesifikasinya dan akan memiliki mutu yang rendah, jika tidak sesuai dengan spesifikasinya. Mutu desain dan mutu kesesuaian mencerminkan penggunaan yang berbeda dari definisi mutu.

\section{PEMBAHASAN}

\section{Pelopor Mutu}

Frederick W. Taylor (1986-1915) dalam bukunya The Principle of Scientific Management.Mengemukakan hal berikut.

1. Tugas harian. Setiap orang dalam setiap organisasi harus mempunyai tugas yang terdefinisi dengan jelas yang harus diselesaikan dalam satu hari.

2. Kondisi standar. Pekerja harus mempunyai alat standar dan kondisinya untuk menyelesaikan suatu pekerjaan.

3. Upah yang tinggi untuk sukses. Penghargaan yang signifikan harus dibayar untuk suatu tugas atau pekerjaan yang sukses.

4. Kerugian yang besar untuk kegagalan. Kegagalan dalam menjalankan tugas atau pekerjaan harus diperhitungkan secara perseorangan.

Walter A. Shewhart (1891-1967) dalam bukunya The Economic Control of Quality of Manufactured Product menyatakan bahwa terdapat variasi dalam setiap pembuatan barang dan variasi tersebut dapat diketahui dengan aplikasi alat statistik sederhana seperti pengambilan contoh (sampling) dan analisis probabilitas. 
David A. Garvin (1988) dalam bukunya Managing Quality: The Strategic and Com petitive Edge mengemukakan delapan dimensi mutu.

1. Kinerja (Performance)

Berhubungan dengan karakteristik operasi primer produk. Sebagai contoh, di dalam televisi, performance berarti kejelasan suara dan gambar, warna, dan kemampuan untuk menerima sinyal dari jarak tertentu. Dalam industri jasa, seperti penerbangan, performance berarti layanan yang cepat.

\section{Fitur (Feature)}

Fitur merupakan aspek kedua dari performance. Contohnya, sarapan pagi gratis di hotel, minum gratis di pesawat terbang.

3. Reliabilitas (Reliability)

Dimensi ini berhubungan dengan probabilitas bahwa suatu produk tidak akan rusak pada jangka waktu tertentu.

4. Kesesuaian (Conformance)

Tingkat produk atau jasa memenuhi spesifikasinya.

5. Umur (Durability)

Ukuran umur produk.

6. Kemudahan perbaikan (Serviceability) seperti kecepatan, kompetensi, dan kemudahan untuk perbaikan.

7. Estetika (Aesthetic)

Ukuran dari bagaimana suatu produk dapat dilihat, dirasakan, dicicipi (masakan), dicium (parfum).

8. Mutu yang dipersepsikan (Perceived Quality)

Konsumen tidak selalu mempunyai informasi yang lengkap tentang produk atau jasa. Durability dari suatu produk, misalnya, tidak siap untuk diobservasi - hal itu harus ada pengaruh dari berbagai aspek yang terlihat (tangible) dan tidak telihat (intangible) dari produk tersebut. Dalam hal ini, imajinasi, periklanan, dan nama merek-mempengaruhi mutu dari kenyataannya-menjadi kritis. Impresi pelanggan dari mutu adalah esensi mutu yang dipersepsikan.

Dr. W. Edward Deming (1982-1986)

Deming mendefinisikan mutu sebagai pengembangan yang terus menerus dari suatu sistem yang stabil. Definisi itu menekankan pada dua hal berikut. 
1. Semua sistem (administrasi, desain, produksi, dan penjualan) harus stabil. Hal itu memerlukan pengukuran yang diambil dari atribut mutu di seluruh perusahaan dan dipantau setiap waktu.

2. Perbaikan yang terus menerus dari berbagai sistem untuk mengurangi penyimpangan dan lebih memenuhi kebutuhan pelanggan.

Empat belas Prinsip Manajemen Deming sebagai berikut.

1. Menciptakan kegunaan yang konstan terhadap perbaikan produk dan jasa.

2. Mengambil filosofi baru dengan menolak kebiasaan penerimaan kesalahan, kerusakan, dan penundaan.

3. Menghilangkan ketergantungan pada inspeksi massal.

4. Meminimumkan biaya total.

5. Perbaikan secara konstan, dan selamanya, sistem produksi untuk memperbaiki mutu dan produktivitas dan secara konstan mengurangi biaya.

6. Pelatihan pada semua bidang kerja untuk semua karyawan.

7. Menitikberatkan manajemen dan penyelia (supervisor) pada kepemimpinan karyawan untuk membantu mereka melakukan pekerjaan dengan lebih baik.

8. Menghilangkan ketakutan. Jangan memarahi karyawan untuk masalah sistem. Kembangkan komunikasi 2 arah yang efektif. Hilangkan management by control.

9. Singkirkan penghalang antardepartemen. Kembangkan kerja sama antara area yang berbeda, seperti riset, desain, produksi, dan penjualan.

10. Hilangkan program, desakan, dan slogan yang memerlukan tingkat produksi baru tanpa adanya metode yang lebih baik.

11. Hilangkan kuota, standar kerja, dan tujuan yang berubah-ubah yang berinterferensi dengan mutu. Sebagai gantinya, kepemimpinan dan perbaikan terus-menerus dari proses kerja.

12. Singkirkan barrier (sistem yang salah dan manajemen yang salah) yang menghilangkan kebanggaan karyawan akan pekerjaannya.

13. Kembangkan pendidikan dan perbaikan diri terus menerus dari seluruh karyawan.

14. Ajak semua karyawan pada implementasi keempat belas prinsip ini.

Dr. Joseph M. Juran (1954) dalam bukunya Juran on Leadreship for Quality mengungkapkan Trilogi Juran sebagai berikut.

1. Perencanaan Mutu

Suatu proses yang mengidentifikasikan pelanggan, persyaratan pelanggan, fitur produk, dan jasa yang diharapkan pelanggan, dan proses untuk menyampaikan produk atau jasa dengan atribut yang benar dan memberikan fasilitas untuk mentransfer pengetahuan ini kepada bagian produksi.

2. Kendali Mutu.

Suatu proses produksi diuji dan dievaluasi terhadap persyaratan-persyaratan asalnya yang diminta oleh pelanggan. Masalah-masalah dideteksi untuk kemudian diperbaiki.

3. Peningkatan Mutu yang meliputi alokasi sumber daya, memberikan tugas kepada seseorang untuk mendorong suatu proyek, pelatihan yang digunakan untuk mendorong suatu proyek, dan membuat sutu struktur umum yang permanen untuk meningkatkan mutu dan mempertahankan yang telah dicapai. 
Philip B. Crosby (1979) dalam bukunya Quallity is Free mengungkapkan empat Dalil Mutu seperti berikut ini.

1. Definisi mutu adalah kesesuaian dengan persyaratan.

2. Sistem mutu adalah pencegahan.

3. Standar kerja adalah Tanpa Cacat (Zero Defect).

4. Pengukuran mutu adalah biaya mutu.

Pendekatan lain dari mutu adalah "Zero Defect” atau tanpa cacat yang dikemukakan oleh Philip B. Crosby (1979) atau membuatnya benar sejak pertama kali (make it right the first time) yang dijabarkan ke dalam 14 elemen proses perbaikan mutu.

1. Komitmen Manajemen (Management Commitment). Pastikan bahwa manajemen senior mengetahui bagaimana pencegahan kesalahan dapat memperbaiki mutu dan mengurangi biaya. Susun kebijakan mutu yang menyatakan bahwa setiap individu harus sungguh-sungguh memenuhi persyaratan kerja yang diperlukan atau diubah menjadi apa yang kita dan pelanggan perlukan. Menyetujui bahwa perbaikan mutu merupakan cara yang praktis untuk meningkatkan keuntungan.

2. Tim Perbaikan Mutu (Quality Improvement Team). Tim ini terdiri dari 1 anggota dari setiap departemen dalam perusahaan. Seseorang dapat ditunjuk yang sepakat agar departemen mengambil tindakan, terutama departemen pusat. Kegunaan tim ini untuk mengimplementasikan program mutu ke seluruh bagian perusahaan.

3. Pengukuran Mutu (Quality Measurement). Mengembangkan pengukuran mutu dalam semua bagian perusahaan. Pengukuran ini digunakan untuk menentukan tindakan perbaikan dan mengukur kemajuannya di waktu-waktu yang akan datang. Pengukuran tidak hanya dikembangkan untuk produk saja tetapi juga pada operasi di bidang jasa, kantor, dan juga untuk para penjual.

4. Evaluasi Biaya Mutu (Cost of Quality Evaluation). Biaya mutu harus didefinisikan. Akuntan harus memikul tanggung jawab atas pengukuran mutu karena hal ini menghilangkan suatu suspected bias. Manajemen akan perlu untuk terlibat tetapi praktik akuntansi yang lalu berubah untuk mencerminkan biaya mutu yang sebenarnya.

5. Kesadaran Mutu (Quality Awareness). Dalam langkah ini, karyawan dibuat agar sadar akan program perbaikan mutu melalui penyelia mereka. Program ini bukan merupakan program motivasi tetapi lebih ditekankan pada usaha untuk menunjukkan kepada pekerja dengan akibat mutu yang rendah terhadap pelanggan, biaya, persaingan, dan pekerjaan mereka.

6. Tindakan Perbaikan (Corrective Action). Tindakan perbaikan ini harus diusulkan oleh para karyawan dan penyelia. Pertemuan mingguan diadakan pada setiap level untuk membahas masalah mutu.

7. Komite Ad Hoc untuk Program Zero Defect. Tiga atau empat anggota tim perbaikan mutu, ditugaskan pada Ad Hoc Committee untuk menginvestigasi konsep Zero Defect dan mencari cara untuk mengkomunikasikan program kepada karyawan (melalui pertemuan, poster, dan sebagainya). Program ini bukan relasi publik melainkan usaha untuk menerangkan bagaimana segala sesuatu harus dikerjakan dengan benar sejak pertama kali.

8. Pelatihan Penyelia (Supervisor Training). Program yang formal diadakan untuk mendidik para manajer pada setiap level mengenai konsep Zero Defect.

9. Hari Zero Defect. Satu hari yang khusus ditentukan untuk menjelaskan kepada seluruh karyawan mengenai Zero Defect sehingga mereka mengetahui konsepnya dengan cara yang sama. Standar Zero Defect harus secara tegas ditentukan pada hari tersebut. 
10. Penentuan Sasaran (Goal Setting). Penyelia minta kepada setiap pekerja untuk menentukan sasaran mutu untuk 30, 60, dan 90 hari. Sasaran itu harus dapat diukur dan spesifik.

11. Penghapusan Penyebab Kesalahan ( Error Cause Removal ). Setiap pekerja diminta untuk menjelaskan masalah yang dihadapi. Kemudian, kelompok fungsional tertentu ditugaskan untuk memeriksa setiap masalah yang terjadi dan mengusulkan cara pemecahannya.

12. Penghargaan/pengakuan (Recognition). Penghargaan diperlukan untuk melengkapi tindakan yang positif dalam menghilangkan penyebab kesalahan. Berbagai macam penghargaan dapat diberikan, misalnya dalam bentuk cincin emas, makan malam, atau benda-benda lainnya.

13. Dewan Mutu (Quality Council). Profesional mutu dan pemimpin-pemimpin tim dari berbagai bagian membentuk dewan mutu. Mereka mengadakan pertemuan secara periodik untuk saling menyampaikan ide dan berkomunikasi mengenai program masing-masing.

14. Lakukan Berulang Kali (Do It Over Again). Program yang khusus memerlukan waktu 1 tahun sampai 18 bulan. Selama kurun waktu tersebut, pengetahuan tentang program dapat mengalami perubahan. Program harus dimulai lagi dengan tim yang baru. Hari Zero Defect (ZD) harus diadakan setahun sekali seperti hari ulang tahun. Program ZD harus terus menerus diadakan sehingga merupakan budaya perusahaan. Jika mutu bukan merupakan pandangan hidup (way of life) maka tidak akan ada perbaikan.

\section{Standar Sistem Manajemen Mutu Internasional}

1. ISO9001 - Spesifikasi sistem mutu untuk desain/pengembangan, produksi, pemasangan, dan layanan.

2. ISO9002 - Spesifikasi sistem mutu untuk produksi dan pemasangan.

3. ISO9003 - Spesifikasi sistem mutu untuk pemeriksaan dan pengujian akhir.

Pengelolaan Mutu Menurut Philip B. Crosby sebagai berikut.

\section{Semua pekerjaan adalah suatu proses}

Setiap pekerjaan adalah suatu proses dan merupakan rangkaian dari kegiatan yang akan menghasilkan suatu hasil akhir. Hasil akhir itu dapat berupa produk atau jasa yang akan memuaskan kebutuhan dan keinginan pelanggan. Untuk memenuhi keinginan pelanggan, harus diidentifikasikan persyaratannya. Misalnya, jika pelanggan menginginkan mobil "merah" atau janji pada jam "09.30 WIB” dan "lima kg“ adalah persyaratan, itu semua adalah keinginan pelanggan untuk produk atau jasa.

Mengetahui persyaratan pada pekerjaan, akan membantu untuk memenuhi keinginan pelanggan dan mencegah timbulnya masalah. Hal itu merupakan dasar dari perbaikan mutu dalam semua pekerjaan. 
Transaksi dalam Pekerjaan

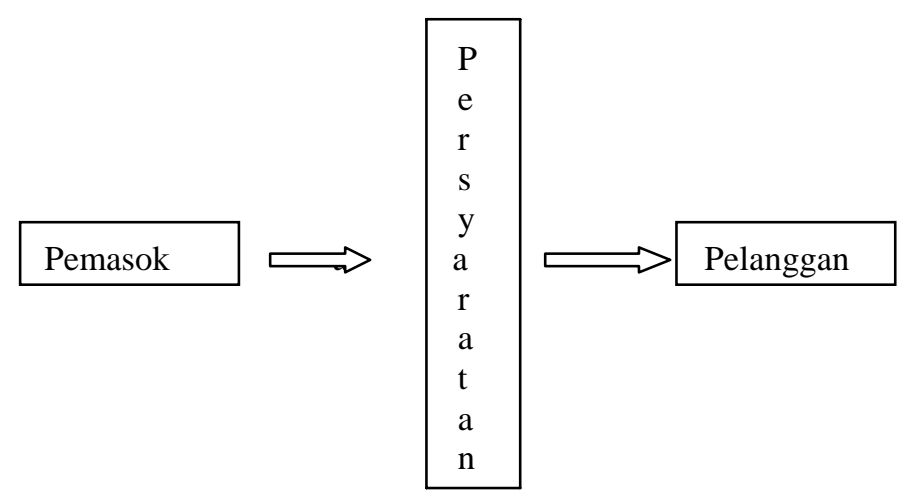

Ada empat dalil mutu yang akan mengarahkan setiap usaha untuk melaksanakan, mengatur, dan meningkatkan pekerjaan.

\section{Definisi Mutu}

Mutu tidak cukup didefinisikan dengan baik sekali, baik, atau indah. Mutu didefinisikan sebagai kesesuaian dengan persyaratan (conformance to requirements). Setiap produk, jasa, atau proses yang sesuai dengan persyaratan-persyaratan disebut sebagai produk, jasa, atau proses yang bermutu.

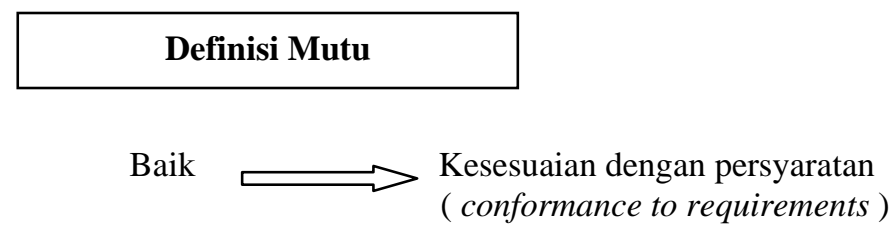

\section{Sistem Mutu}

Suatu cara untuk menjamin mutu adalah dengan penilaian atau inspeksi. Hasil inspeksi tersebut digunakan untuk membuat suatu keputusan. Inspeksi hanya memisahkan yang baik dan yang buruk saja tetapi tidak membantu dalam peningkatan. Untuk peningkatan mutu, dibutuhkan suatu kebijakan dan sistem yang berdasarkan pada prinsip pencegahan. Pencegahan meliputi komunikasi, perencanaan, pembuktian, dan bekerja untuk menghilangkan kemungkinan terjadinya nonconformance (ketidaksesuaian).

Sistem untuk Peningkatan Mutu

Penilaian 


\section{Standar Karya}

Dalil mutu yang ketiga menjelaskan kegunaan standar dan suatu karya dapat dibandingkan. Ada standar karya untuk mutu, biaya, dan jadwal. Idealnya, semua pekerjaan harus sesuai dengan persyaratan dan tepat waktu sesuai dengan anggaran. Akan tetapi, pada keadaan yang sebenarnya hal itu tidak selalu terjadi. Kadang-kadang keadaan memaksa untuk mengambil keputusan dengan mengorbankan mutu pekerjaan demi mencapai biaya dan jadwal yang telah ditetapkan. Namun, tanpa kesepakatan yang bulat terhadap mutu, sangat sulit mencapai semua persyaratan, termasuk biaya dan jadwal.

Untuk membuat komitmen ini, diperlukan standar karya yang dapat mengerti semua orang, yaitu “Zero Defect”.

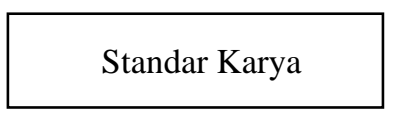

Itu sudah mendekati

Standar karya yang konvensional untuk mutu dapat diungkapkan dengan kalimat “mendekati”. Dengan kata lain, semua persyaratan harus dipenuhi kadang-kadang atau seluruh persyaratan itu harus dipenuhi selamanya. Akan tetapi jika diinginkan, pekerjaan menjadi bermutu, setiap nonconformance tidak dapat diterima, kesalahan akan dicegah dan pelanggan akan menerima produk atau jasa yang sesuai dengan standar karya Zero Defect.

\section{Pengukuran}

Cara yang paling baik untuk pengukuran mutu adalah menghitung berapa biaya yang dikeluarkan karena melakukan pekerjaan yang salah. Pengukuran ini disebut Price of Nonconformance (PONC).

\section{Pengukuran Mutu}

Indeks $\longrightarrow$ Price of Nonconformance

Kegiatan PONC meliputi proses ulang, memacu pengiriman, kerja ulang, kelebihan stok gudang, penganan keluhan, waktu kerusakan (down time), dan pengembalian (retur).

\section{PENUTUP}

1. Manajemen Mutu Terpadu (Total Quality Management, TQM) merupakan usaha untuk memenuhi kebutuhan pelanggan dengan biaya serendah mungkin.

2. Ada beberapa definisi mutu yang dikemukakan oleh beberapa pelopor mutu, antara lain Frederick W. Taylor, Walter A. Shewhart, David A. Garvin, Edward Deming, dan Philip B. Crosby. 
3. Definisi mutu menurut Philip B. Crosby adalah kesesuaian dengan persyaratan.

4. Ada empat dalil mutu menurut Philip. B. Crosby sebagai berikut.
a. Definisi mutu adalah kesesuaian dengan persyaratan.
b. Sistem mutu adalah pencegahan.
c. Standar karya adalah Zero Defect.
d. Pengukuran mutu adalah biaya mutu (Price of Nonconformance, PONC).

\section{DAFTAR PUSTAKA}

Crosby, Philip B. 1979. Quality is Free: The Art of Making Quality Certain. New York.

Faure, Lesley Munro dan Malcolm Munro-Faure. 1999. Implementing Total Quality Management, alih bahasa oleh Sularno Tjiptowardojo. Cetakan II. Jakarta: PT Elex Media Komputindo.

Garvin, David A. 1988. Managing Quality: The Strategic and Competitive Edge. New York.

Heizer, Jay and Barry Render. 1988. Production and Operations Management. USA: Allyn and Bacon Inc.

Juran, J.M. Juran on Leadership for Quality: 1989. An Executive Handbook. New York.

Schroeder, Roger G. 1993. Operations Managemen: Decision Making in the Operation Functions. $4^{\text {th }}$ Edition. USA: McGraw-Hill.

Tenner, Arthur R. dan Irving J. Detoro. 1992. Total Quality Manajement: Three Steps to Continuous Improvement. New York: Addison-Wesley Publishing Company. 